\title{
PERAN RADIO KOMUNITAS DALAM PENYULUHAN PERTANIAN
}

\section{THE ROLE OF COMMUNITY RADIO IN AGRICULTURAL EXTENSION}

\author{
Nurlaili dan Andi Warnaen \\ Politeknik Pembangunan Pertanian Malang \\ e-mail: nurlaili@polbangtanmalang.ac.id
}

\begin{abstract}
ABSTRAK
Radio komunitas merupakan radio penyiaran yang didirikan oleh komunitas tertentu, bersifat independen dan tidak komersial, dengan daya pancar rendah, luas jangkauan wilayah terbatas serta untuk melayani kepentingan komunitasnya. Radio komunitas merupakan salah satu media untuk menyebarkan informasi dan inovasi di bidang pertanian. Penelitian ini bertujuan untuk mengkaji peranan radio komunitas dalam penyuluhan pertanian. Penelitian ini adalah penelitian deskriptif kualitatif. Penelitan dilakukan di Radio Komunitas Pass FM Kota Batu. Informan dalam penelitian ini adalah pendiri, pengurus serta anggota komunitas Radio Komunitas Pass FM. Teknik pengumpulan data yang dilakukan adalah dengan teknik observasi, wawancara, Focus Group Discussion (FGD) dan dokumentasi. Data kemudian dianalisis menggunakan model analisis data interaktif Miles dan Huberman. Hasil penelitian menunjukkan bahwa radio komunitas memiliki peran dalam penyuluhan pertanian, yaitu sebagai media dan metode penyuluhan pertanian yang bersifat partisipatif. Hal ini dikarenakan materi atau konten radio komunitas sesuai dengan kondisi dan kepentingan komunitas, dirancang bersama anggota komunitas (partisipatif), interaktif dan mendapat feedback langsung dari komunitas. Dengan pendampingan oleh penyuluh dan lembaga penyuluhan (BPP), radio komunitas dapat berperan maksimal dalam penyuluhan pertanian baik sebagai media maupun metode penyuluhan pertanian.
\end{abstract}

Kata Kunci: Peran Radio Komunitas, Penyuluhan Pertanian, Radio Komunitas

\begin{abstract}
Community radio is a radio broadcasting which was established by a particular community, independent and not commercial, with a low emittance, limited coverage area, and serve the interests of the community. Community radio is one of the media to disseminate information and innovation in agriculture. This study aims to assess the role of community radio in agricultural extension. This study was descriptive qualitative research. Research carried out in Pass FM Community Radio Kota Batu. Informants in this study are the founder, the radio board and community members of Pass FM Community Radio. The Techniques of data collection using observation, interviews, focus group discussion (FGD) and documentation. Data were analyzed using a model of interactive data analysis by Miles and Huberman. The results showed that community radio has a role in agricultural extension, as a medium and a method of participatory agricultural extension. This is because of the material or content of community radio in accordance with the conditions and the interests of the community, designed in collaboration with community members (participatory), interactive and get direct feedback from the community. With assistance by the extension worker and the extension institution (BPP), community radio can play a maximum in agricultural extension both as a medium and a method of agricultural extension.
\end{abstract}


Keywords: The Role of Community Radio, agricultural extension, Community Radio

\section{PENDAHULUAN}

Proses Pembangunan memerlukan fasilitator pembangunan, penyatu sistem tradisional dan modern, dan mengikutsertakan masyarakat di tingkat akar rumput secara aktif dalam program-program pembangunan (Harun dan Ardianto, 2011). Proses pembangunan memerlukan media rakyat yang dapat memfasilitasi masyarakat tingkat bawah untuk menyuarakan aspirasiya, media swasta atau pemerintah lebih didominasi oleh pihak-pihak penguasa atau kalangan elit saja dalam menyuarakan aspirasi, masyarakat hanya dijadikan objek oleh pemerintah dan pengusaha untuk kepentingannya. Media tidak hanya sebagai alat hiburan atau penyalur aspirasi saja, media mempunyai peranan yang sangat penting dalam membangun masyarakat. Media harus menjadi media pendidikan dan penggerak pembangunan.

Media yang dapat dikembangkan dalam proses pembangunan masyarakat bawah salah satunya adalah media komunitas, yang memungkinkan masyarakat kecil terlibat dalam merencanakan dan melaksanakan program penyiaran yang mendidik dan membangun. Lembaga penyiaran komunitas adalah lembaga penyiaran berbentuk badan hukum Indonesia, didirikan oleh komunitas tertentu, bersifat independen, dan tidak komersial, dengan daya pancar rendah, luas jangkauan wilayah terbatas, serta untuk melayani kepentingan komunitasnya. Undang-undang Republik Indonesia Nomor 32 Tahun 2002 tentang penyiaran telah mengakui keberadaan lembaga penyiaran komunitas sebagaimana lembaga penyiaran publik, swasta dan berlangganan dan penyelenggaraannya telah diatur oleh Peraturan Pemerintah Nomor 51 Tahun 2005. Salah satu lembaga penyiaran komunitas adalah Radio Komunitas.

Proses fasilitasi dan pendampingan masyarakat bawah atau pedesaan dapat terwujud salah satunya melalui proses penyuluhan pertanian, masyarakat akan di dampingi supaya berdaya dalam mengusahakan kesejahteraan hidupnya. Proses penyuluhan pertanian memerlukan media yang partisipatif dan dapat menyalurkan aspirasi masyarakat sesuai kepentingan masyarakat itu sendiri salah satunya adalah pemanfaatan radio komunitas dalam proses penyuluhan pertanian. Radio komunitas memiliki karakteristik yang berbeda dengan siaran radio komersial. Terutama pada aspek kepemilikan, pengawasan, serta tujuan dan fungsinya. Perbedaan tersebut diantaranya: radio komunitas bersifat independen, tidak komersial, daya pancar rendah, luas jangkauan wilayah terbatas, dan untuk melayani kepentingan komunitasnya. Berdasarkan latarbelakang tersebut, maka penelitian ini bertujuan untuk mengkaji peranan Radio Komunitas dalam penyuluhan pertanian di Kota Batu.

\section{METODE PENELITIAN}

Penelitian ini dilaksanakan di Radio Komunitas Pass FM, di desa Tulungrejo, Kecamatan Bumiaji, Kota Batu, Jawa Timur. Radio Komunitas Pass FM dipilih berdasarkan komunitasnya yang terdiri dari para petani. Penelitian ini bersifat deskriptif kualitatif. Penelitian kualitatif deskriptif akan melakukan penggambaran secara mendalam tentang situasi atau proses yang akan diteliti (Idrus, 2009).

Pemilihan radio komunitas, lokasi penelitian dan narasumber atau informan dalam penelitian ini dilakukan dengan pendekatan purposive sampling. Narasumber atau informan dalam penelitian ini adalah pendiri radio komunitas Pass FM, pengurus radio komunitas dan anggota radio komunitas Pass FM. Tujuannya adalah mengetahui peranan Radio Komunitas Pass FM Kota Batu dalam penyuluhan pertanian.

Teknik pengumpulan data yang dilakukan adalah dengan teknik observasi, wawancara, Focus Group Discussion (FGD) dan dokumentasi. Data kemudian dianalisis 
menggunakan model analisis data interaktif Miles dan Huberman. Menurut Miles dan Huberman (dalam Idrus, 2009) model interaktif ini terdiri dari tiga hal utama, yaitu: (1) reduksi data; (2) penyajian data; dan (3) penarikan kesimpulan/verifikasi.

\section{HASIL DAN PEMBAHASAN}

\section{Radio Komunitas Pass FM Kota Batu}

Radio Komunitas memiliki

karakteristik yang berbeda dengan siaran radio komersial. Terutama pada aspek kepemilikan, pengawasan serta tujuan dan fungsinya. Radio Komunitas adalah stasiun siaran radio yang dimiliki, dikelola, diperuntukkan, diinisiatifkan dan didirikan oleh sebuah komunitas. Radio Komunitas juga sering disebut sebagai radio sosial, radio pendidikan, atau radio alternatif. Intinya, radio komunitas adalah "dari, oleh, untuk dan tentang komunitas".

Radio Komunitas Pass FM Kota Batu didirikan pada bulan Agustus 2012. Basisnya berdasarkan hobi personal. Dengan upaya sosialisasi kepada warga sekitar untuk membentuk radio komunitas serta upaya pengurusan izin siaran ke KPID Jawa Timur di Surabaya, hingga tanggal 17 Juni 2015 Izin Siaran Radio (ISR) Radio Komunitas Pass FM Kota Batu terbit. Radio Komunitas Pass FM berlokasi di Jl. P. Diponegoro IV/51 Gondang, Desa Tulungrejo, Kecamatan Bumiaji, Kota Batu. Visi Radio Komunitas Pass FM adalah "Mewujudkan komunitas petani yang komunikatif, kreatif dan partisipatif". Sedangkan misi Radio Komunitas Pass FM adalah "Melalui Radio Komunitas wujudkan komunitas petani sejahtera dan berperan aktif dalam membangun partisipasi kepada masyarakat". Radio Komunitas Pass FM Kota Batu adalah anggota Jaringan Radio Komunitas Indonesia (JRKI) Jawa Timur.

Program acara Radio Komunitas Pass FM terdiri dari program siaran harian, mingguan dan bulanan. Siaran harian dimulai pada pukul 06.00 sampai dengan pukul 24.00 WIB. Beberapa acara siaran Radio Pass FM diantaranya acara hiburan, siaran budaya seperti wayang kulit, dan talkshow seputar pertanian, wisata dan perdagangan. Selain kegiatan on air, Radio Pass FM juga mengadakan kegiatan non air seperti Rapat Pengurus Radio, Arisan Pengurus dan Anggota Radio dan kegiatan-kegiatan insidential. Anggota komunitas Radio Pass FM adalah para petani apel, petani bunga, petani sayuran serta pedangang di sekitar Kota Batu.

\section{Peran dan Fungsi Radio Komunitas}

Sebagai media massa, Radio Komunitas Pass FM memiliki beberapa peran atau fungsi. Menurut Alexis S.Tan (1981) dalam Nurudin (2007) ada empat fungsi sekaligus peran media massa, antara lain: (1) Memberi informasi, (2) Mendidik, (3) Mempersuasi dan (4) Memberi hiburan. Hasil penelitian mengungkap bahwa:

1) Radio Pass FM Kota Batu berperan dalam memberikan informasi yang umunya dibutuhkan warga atau komunitasnya, seperti informasi tentang pertanian, perkembangan pasar, kesehatan, wisata dan berita sekitar daerah lokal dan nasional. Namun pemberian informasi ini tidak dikemas dalam acara khusus, tetapi diintegrasikan dengan acara hiburan (musik). Belum ada jadwal yang jelas dan tetap untuk acara pemberian informasi. Hal ini dikarenakan terkendala terbatasnya pemateri.

2) Radio Pass FM Kota Batu berperan dalam memberi informasi pendidikan kepada warga sekitar dan komunitasnya. Dalam kurun waktu dua tahun ini Radio Pass FM bekerjasama dengan lembaga pemerintah seperti KPK dan BKKBN Provinsi Jawa Timur. Sehingga sering melakukan penyuluhan tentang pemberantasan korupsi dan Keluara Berencana (KB) baik dalam bentuk acara talkshow maupun melalui iklan layanan masyarakat. Untuk program penyuluhan pertanian, Radio Pass FM bekerjasama dengan Sekolah Tinggi Penyuluhan Pertanian (STPP) Malang memberikan penyuluhan pertanian, khususnya 
peternakan melalui acara siaran pedesaan, talkshow, dan pemutaran sandiwara radio. Meskipun setiap program acara penyuluhan mendapatkan respon yang baik dari para pendengar, namun pelaksanaannya belum terprogram dan terjadwal secara rutin, umumnya bersifat aksidental.

3) Radio Pass FM Kota Batu berperan dalam mempersuasi warga atau komunitasnya. Sebagai lembaga penyiaran komunitas, Radio Komunitas Pass FM dilarang melakukan siaran iklan dan atau siaran komersial lainnya, kecuali iklan layanan masyarakat. Iklan layanan masyarakat yang diselenggarakan oleh Radio Komunitas Pass FM bekerja sama dengan KPK dan BKKBN Provinsi Jawa Timur, berupa iklan layanan masyarakat tentang pemberantasan korupsi dan Keluarga Berencana (KB). Josep A.Devito (1997) menyatakan bahwa fungsi persuasi dianggap sebagai fungsi yang paling penting dari komunikasi massa. Persuasi bisa datang dari berbagai macam bentuk: (1) mengukuhkan atau memperkuat sikap, kepercayaan, atau nilai seseorang; (2) mengubah sikap, kepercayaan, atau nilai seseorang; (3) menggerakkan seseorang untuk melakukan sesuatu; dan (4) memperkenalkan etika, atau menawarkan sistem nilai tertentu (Nurudin, 2007).

4) Radio Pass FM Kota Batu berperan dalam memberikan hiburan kepada warga atau komunitasnya. Hiburan merupakan acara Radio Komunitas Pass
FM Kota Batu yang paling dominan. Wujudnya berupa pemutaran musik, baik musik daerah, nasional maupun musik barat. Jenis hiburan yang disiarkan oleh Radio Komunitas Pass FM sangat beragam, mulai dari musik daerah, musik dangdut, musik pop Indonesia, musik barat, musik religi, karaoke hingga wayang kulit. Jenis hiburan yang disiarkan sangat tergantung dari penyiar radio yang bertugas.

Ketentuan program siaran, idealnya sesuai dengan ruh/semangat pendirian radio komunitas. Untuk itu informasi yang disajikan harus menyentuh kebutuhan komunitasnya. Prinsip proksimitas atau kedekatan secara psikologis (fisik dan budaya) anatar radio dengan warganya, menjadi komponen utama kelebihan radio komunitas dibandingkan dengan jenis radio lainnya. Selain itu, karena radio komunitas umumnya didirikan untuk kaum marjinal, pasif, para grass root atau kaum papa, maka salah satu tujuan utamanya adalah pemberdayaan (empowering) warga (Rachmiatie, 2007).

\section{Peran Radio Komunitas dalam penyuluhan Pertanian}

Radio komunitas merupakan lembaga penyiaran yang diselenggarakan dari, oleh dan untuk komunitas itu sendiri, sehingga radio komunitas dapat berperan maksimal dalam penyuluhan pertanian baik sebagai media maupun metode penyuluhan pertanian. Beberapa kelebihan dan kekurangan radio komunitas sebagai media maupun metode penyuluhan pertanian:

Tabel 1. Kelebihan dan Kekurangan Radio Komunitas sebagai Media dan Metode Penyuluhan

\begin{tabular}{lll}
\hline Kelebihan & \multicolumn{1}{c}{ Kekurangan } \\
\hline 1. Radio dapat mencapai pendengar dalam 1. & $\begin{array}{l}\text { Radio tidak dapat memberikan } \\
\text { informasi secara terperinci, sebab para }\end{array}$ \\
jumlah besar dengan lebih cepat dan lebih \\
murah daripada sarana komunikasi yang lain \\
$\begin{array}{l}\text { pendengarnya segera lupa dan } \\
\text { (Depari dan MacAndrews, 1988) }\end{array}$ \\
$\begin{array}{l}\text { 2. Radio dapat menumbuhkan kesadaran } \\
\text { pembangunan dan merangsang rasa } \\
\text { keterlibatan (Depari dan MacAndrews, } \\
\text { 1988) }\end{array}$
\end{tabular}


Peran Radio Komunitas dalam Penyuluhan Pertanian ....................... (Nurlaili dan Andi Warnaen)

3. Informasi/materi penyuluhan sesuai dengan kondisi dan kepentingan komunitas (Rachmiatie, 2007)

4. Bersifat interaktif, feedback cenderung langsung (Rachmiatie, 2007) dan minat dalam proses adopsi inovasi.

Memerlukan kombinasi dengan media

dan metode penyuluhan lain

(Ismulhadi, 2013)

\section{a. Radio komunitas sebagai media penyuluhan pertanian.}

Media penyuluhan pertanian merupakan salah satu komponen dalam kegiatan penyuluhan pertanian yang memiliki peranan dan kedudukan yang sama dengan komponen-komponen lain, seperti subjek dan objek penyuluhan, materi penyuluhan serta metode penyuluhan. Seiring perkembangan teknologi komunikasi dan informasi, media penyuluhan pertanian mengalami perkembangan teknologi dengan sentuhansentuhan teknologi media massa modern. Salah satu media komunikasi modern yang dapat dijadikan media penyuluhan pertanian adalah radio komunitas.

Radio Komunitas merupakan salah satu lembaga penyiaran yang dapat dijadikan sebagai media penyuluhan untuk menyebarkan informasi teknologi dan inovasi di bidang pertanian. Media penyuluhan pertanian adalah segala bentuk benda yang berisi pesan atau informasi yang dikemas sedemikian rupa sehingga dapat membantu kegiatan penyuluhan pertanian. Media penyuluhan pertanian berguna untuk mengefektifkan komunikasi antara sumber informasi dan penerima informasi.

Radio komunitas memiliki potensi yang sangat baik apabila dikembangkan sebagai media penyuluhan pertanian. Hal ini dikarenakan konten/materi radio komunitas yang terpilih sesuai dengan kondisi dan kepentingan komunitas serta isi dirancang oleh dan bersama anggota komunitas. Namun selama ini di Radio Komunitas Pass FM Kota Batu terkendala masalah pengisi acara serta materi penyuluhan. Untuk itu diperlukan pendampingan dari penyuluh pertanian (PPL) dan lembaga penyuluhan (BPP) terutama yang bertugas di wilayah Kecamatan Bumiaji, Kota Batu. Berdasarkan potensi tersebut maka media penyuluhan berupa radio komunitas dapat memudahkan penyuluh untuk menyampaikan informasi tentang inovasi-inovasi pertanian secara cepat dan terprogram.

Penyuluhan pertanian merupakan salah satu bentuk pendidikan non formal. Pemanfaatan radio komunitas diyakini mampu memberikan kontribusi positif terhadap praktek pendidikan non formal. Sebagai media massa yang memiliki keluasan jangkauan dan jaringan, radio komunitas diharapkan mampu menjembatani berbagai keterbatasan yang dihadapi oleh institusi penyelenggara layanan pendidikan non formal. Dalam keterbatasan lokasi, ruang dan waktu, komunitas sasaran diharapkan mampu mengakses, berpartisipasi, dan mengelola sendiri radio komunitas sebagai media pembelajaran yang efektif (Pramudia, 2007).

\section{b. Peran radio komunitas sebagai metode penyuluhan pertanian.}

Metode penyuluhan pertanian diartikan sebagai cara atau teknik penyampaian materi penyuluhan pertanian yang dilakukan oleh penyuluh pertanian kepada petani-nelayan dan keluarganya, agar mereka tahu, mampu dan mau menggunakan inovasi baru. Cara penyampaian dapat secara langsung atau tidak langsung. Pemilihan metode penyuluhan merupakan syarat mutlak yang harus dilakukan dengan beberapa alasan (Ismulhadi, 2014).

Penyuluhan pertanian melalui radio komunitas memungkinkan untuk berkembangnya metode penyuluhan pertanian yang partisipatif. Hal ini dikarenakan Radio Komunitas didirikan dan dikelola oleh komunitas, sehingga materi siaran/penyuluhan yang disajikan sesuai dengan kebutuhan dan kepentingan komunitas itu sendiri. Karakteristik radio komunitas ini sangat relevan dengan prinsipprinsip metode penyuluhan pertanian partisipatif. Penyuluhan pertanian partisipatif 
adalah kegiatan penyuluhan dengan melibatkan petani di setiap tahapan kegiatan penyuluhan, sehingga kegiatan penyuluhan yang dilaksanakan sesuai dengan kebutuhan petani. Prinsip penyuluhan partisipatif adalah berdasarkan kebutuhan belajar, berorientasi pada tujuan kegiatan penyuluhan, berpusat pada peserta didik, dan berangkat dari pengalaman (Sudjana, 2005). Fraser dan Estrada (2001) mengemukakan bahwa fokus yang khas dari radio komunitas adalah membuat audiens/khalayaknya sebagai protagonis (tokoh utama) melalui keterlibatan mereka dalam seluruh aspek manajemen, dan produksi programnya, serta menyajikan program yang membantu mereka dalam pembangunan dan kemajuan sosial di komunitas mereka.

$$
\text { Radio Pass FM Kota Batu }
$$

bekerjasama dengan STPP Malang dalam memberikan siaran penyuluhan pertanian, khususnya peternakan. Bentuk acara penyuluhannya berupa siaran pedesaan, talkshow serta drama. Respons yang diterima sangat baik dari komunitas pendengar. Hal ini terlihat dari antusias pendengar ketika acara interaktif. Banyak komentar positif serta dukungan untuk merutinkan siaran penyuluhan pertanian di Radio Pass FM. Banyak pula masukan materi-materi penyuluhan pertanian yang dibutuhkan oleh para pendengar. Selain itu banyak yang berharap setelah penyuluhan di radio akan ada penyuluhan pertanian lanjutan berupa diskusi dan demonstrasi. Walaupun program penyuluhan pertanian di Radio Pass FM belum optimal, hal ini menjadi potensi pengembangan radio komunitas sebagai salah satu metode penyuluhan yang bersifat partisipatif.

\section{Permasalahan Radio Komunitas Pass FM Kota Batu}

Pada kenyataannya, Radio Komunitas Pass FM Kota Batu menghadapi banyak permasalahan dalam perkembangannya, diantaranya:

1) Keterbatasan sebuah radio komunitas adalah sifatnya yang tidak komersial. Akibatnya Radio Komunitas Pass FM kesulitan mencari sumber dana. Radio komunitas dilarang melakukan siaran iklan dan/atau siaran komersial lainnya. Sumber pembiayaan radio komunitas berasal dari sumbangan, hibah, sponsor, dan sumber lain yang sah dan tidak mengikat. Selama ini untuk biaya operasional seperti membayar listrik dan pajak Radio Pass FM hanya mengandalkan bantuan dana dari donatur dan dana pribadi dan sukarela dari pengurus radio.

2) Fasilitas yang dimiliki Radio Komunitas Pass FM masih sederhana. Dengan ruangan siaran yang hanya berukuran 1 x 1,5 meter, dan alat siaran sederhana berupa komputer, DVD Player, audio mixer, sound processor dan microphone yang masing-masing berjumlah 1 (satu) unit.

3) Kekurangan tenaga penyiar, baik dari segi kualitas dan kuantitasnya. Jumlah penyiar Radio Komunitas Pass FM berjumlah 10 orang dengan latar pendidikan beragam (SD-SMA) dan pekerjaan yang juga beragam seperti ibu rumah tangga, petani, pedagang, tukang ojek dan PNS. Tidak ada upah/pendapatan tetap dan rutin bagi penyiar di radio komunitas ini. Penyiar radio bersifat sukarela dan berdasarkan hobi/kesenangan mereka saja.

\section{KESIMPULAN}

Peran radio komunitas dalam penyuluhan pertanian adalah sebagai media penyuluhan dan sebagai metode penyuluhan yang bersifat partisipatif. Radio komunitas memiliki potensi yang sangat baik apabila dikembangkan sebagai media dan metode penyuluhan pertanian. Hal ini dikarenakan konten/materi siaran di radio komunitas sesuai dengan kondisi dan kebutuhan komunitas serta ada keterlibatan/partisipasi dari komunitas tersebut. Karakteristik radio komunitas ini sangat relevan dengan prinsip- 
prinsip metode penyuluhan pertanian partisipatif. Sebagai media dan metode penyuluhan pertanian diperlukan pendampingan dari penyuluh pertanian (PPL) dan lembaga penyuluhan (Balai Penyuluhan Pertanian) serta kedepannya Radio Komunitas dapat dikembangkan menjadi bagian dari fasilitas media penyuluhan Balai Penyuluhan Pertanian (BPP) Kecamatan.

\section{DAFTAR PUSTAKA}

Depari, Eduard dan Colin MacAndrews. 1988. Peranan Komunikasi Massa dalam Pembangunan. Suatu Kumpulan Karangan. Gadjah Mada University Press: Yogyakarta

Fraser, Cohn dan Sofia Restrepo Estrada. 2001. Buku Panduan Radio Komunitas. Penerjemah: Tim Jaring Line Jakarta. Tim Komunikasi UNESCO: Jakarta

Harun, Rochajat dan Ardianto Elvinaro. 2011. Komunikasi Pembangunan Perubahan Sosial, Prespektif Dominan, Kaji Ulang dan Teori Kritis. Rajawali Pers: Jakarta

Idrus, Muhammad. 2009. Metode Penelitian Ilmu Sosial. Penerbit Erlangga: Jakarta

Ismulhadi. 2014. Metode Penyuluhan Pertanian I. Sekolah Tinggi Penyuluhan Pertanian Malang: Malang

Nurudin. 2007. Pengantar Komunikasi Massa. Rajawali Pers: Jakarta

Pemerintah Republik Indonesia. Peraturan Pemerintah Republik Indonesia No. 51 Tahun 2005 tentang Penyelenggaraan Penyiaran Lembaga Komunitas. Kementerian Hukum dan HAM RI. Jakarta
Pramudia, Joni Rahmat. 2007. Radio Komunitas untuk Perluasan Pendidikan Non Formal. Jurnal Pendidikan Luar Sekolah Vo. 4 No. 1, April 2007. Unversitas Negeri Yogyakarta: Yogyakarta

Rachmiatie, Atie. 2007. Radio Komunitas, Eskalasi Demokratisasi Komunikasi. Simbiosa Rekatama Media: Bandung

Republik Indonesia. Undang - Undang Republik Indonesia No. 32 Tahun 2002 tentang Penyiaran. Sekretariat Negara. Jakarta

Sudjana. 2005. Strategi Pembelajaran. Falah Production: Bandung 